\title{
MODEL PERSAMAAN STRUKTURAL UNTUK MENGETAHUI PERSEPSI KONSUMEN TERHADAP BUAH IMPOR
}

\author{
I Kadek Teguh Pradana ${ }^{1 \S}$, Ni Ketut Tari Tastrawati ${ }^{2}$, I Putu Eka Nila Kencana ${ }^{3}$ \\ ${ }^{1}$ Program Studi Matematika, Faultas MIPA - Universitas Udayana [Email: teguhpradanatd@gmail.com] \\ ${ }^{2}$ Program Studi Matematika, Faultas MIPA - Universitas Udayana [Email: tastrawati@unud.ac.id] \\ ${ }^{3}$ Program Studi Matematika, Faultas MIPA - Universitas Udayana [Email: i.putu.enk@unud.ac.id] \\ ${ }^{\S}$ Corresponding Author
}

\begin{abstract}
This research is aimed to determine the factors that significantly influence consumer perception in buying imported fruits using structural equation modeling (SEM) analysis. The study use 164 data obtained from questionnaire, which respondents were aged 18 years old or above, from Gianyar Regency, had bought and had felt imported fruits. The study use 4 latent variables (perception, product, personal, culture) with 19 measured variables. The results showed that consumer knowledge about imported fruits (product) and culture about the use of imported fruits in traditional ceremonies (culture) were significantly influence consumer perception about consumption of imported fruit (perception).
\end{abstract}

Keywords: SEM analysis, imported fruits, consumer perception.

\section{PENDAHULUAN}

Buah impor adalah buah-buahan yang di datangkan dari negara lain. Impor buah telah biasa dilakukan di era ini, untuk memenuhi kebutuhan dan keinginan konsumen akan buahbuahan.

Masyarakat Bali dengan adat istiadat yang beragam telah terbiasa menggunakan buah impor sebagai pelengkap sarana upacara. Seiring dengan berkembangnya pengalaman dan pengetahuan konsumen terhadap buah, membuat para konsumen lebih selektif dalam memilih buah-buahan, sehingga akan memilih buah-buahan yang sesuai harapan dan kebutuhannya. Namun hal ini mengakibatkan keresahan apabila buah yang diproduksi atau dijual oleh para petani atau pedagang tidak sesuai harapan konsumen, sehingga petani ataupun pedagang akan mengalami kerugian.

Menurut The Howard and Sheth Model of Buyer Behavior, serta Model Perilaku Konsumen Kerby dalam Dwiastuti, dkk (2012) persepsi konsumen memengaruhi perilaku konsumen dalam memilih suatu produk. Persepsi adalah proses seseorang memilih, mengelola, mengidentifikasi, dan menafsirkan informasi dengan tujuan untuk memahami lingkungannya (Kenyon \& Sen, 2015). Menurut Setiadi (2003) persepsi seseorang dipengaruhi oleh: (1) stimulus, yaitu setiap bentuk fisik, visual atau komunikasi verbal yang dapat memengaruhi tanggapan individu, (2) hubungan stimulus dengan lingkungan (sosial dan budaya), dan (3) kondisi-kondisi dalam individu itu sendiri.

Faktor-faktor persepsi konsumen tidak dapat diukur secara langsung karena berupa konsep (variabel laten) seperti stimulus, individu, dan budaya. Memperhatikan faktorfaktor tersebut, dibutuhkan suatu indikator untuk merefleksikan konsep persepsi.

Structural equation modeling (SEM) adalah bagian dari alat statistika yang mampu menjelaskan hubungan antarvariabel. SEM adalah teknik multivariat yang menggabungkan aspek dari analisis faktor dan regresi berganda yang memungkinkan peneliti untuk memeriksa secara simultan hubungan dependen antara variabel terhitung dengan variabel laten, dan hubungan antarvariabel laten (Hair et al., 2013).

Adapun tujuan dari penelitian ini, yaitu menguji hubungan kausalitas antarkonstruk, 
mengukur kelayakan model dan mengkonfimasinya sesuai dengan data empiris, untuk mengetahui faktor-faktor signifikan yang memengaruhi persepsi konsumen dalam membeli buah impor.

Oleh karena itu, SEM digunakan pada penelitian ini karena SEM tepat digunakan dalam menguji teori, mampu memeriksa secara simultan hubungan dependen antara variabel terhitung dengan variabel laten, dan hubungan antarvariabel laten, serta dapat digunakan untuk mendapatkan justifikasi atas pengujian dengan serangkaian analisis yang kompleks.

Structural equation modeling (SEM) adalah bagian dari alat statistika yang mampu menjelaskan hubungan antarvariabel. SEM adalah teknik multivariat yang menggabungkan aspek dari analisis faktor dan regresi berganda yang memungkinkan peneliti untuk memeriksa secara simultan hubungan dependen antara variabel terhitung dengan variabel laten, dan hubungan antarvariabel laten (Hair JR, et al., 2013).

SEM bertujuan untuk mengestimasi model struktural berdasarkan telaah teoretis yang kuat untuk menguji hubungan kausalitas antarkonstruk serta mengukur kelayakan model dan mengkonfimasinya sesuai dengan data empiris (Sarwono, 2010).

Persepsi menurut Kenyon dan Sen (2015) persepsi adalah proses dimana seseorang memilih, mengelola, mengidentifikasi, dan menafsirkan informasi dengan tujuan untuk memahami lingkungannya. Persepsi bertindak sebagai filter, sehingga mencegah kelelahan dari banyaknya gangguan (rangsangan) di sekitar. Persepsi dapat dibentuk dari belajar, ingatan, dan harapan.

Menurut Setiadi (2003) persepsi seseorang dipengaruhi oleh: (1) stimulus, yaitu setiap bentuk fisik, visual atau komunikasi verbal yang dapat memengaruhi tanggapan individu, (2) hubungan stimulus dengan lingkungan (sosial dan budaya), dan (3) kondisi-kondisi dalam individu itu sendiri.opulasi dan sampel.

Karakteristik stimulus memegang peranan penting dalam merebut perhatian konsumen. Stimuli pemasaran adalah setiap komunikasi atau stimuli fisik yang didesain untuk memengaruhi konsumen. Produk dan komponen-komponennya (seperti kemasan, isi, ciri-ciri fisik) adalah stimuli utama. Komunikasi yang didesain untuk memengaruhi konsumen adalah stimuli tambahan yang merepresentasikan produk seperti kata-kata, gambar, dan simbol atau melalui stimuli lain yang diasosiasikan dengan produk seperti harga, toko, tempat produk dijual dan pengaruh sales (Dwiastuti, Shinta, \& Isaskar, 2012). Dalam penelitian ini, stimulus yang digunakan berupa produk (buah impor) dan selanjutnya akan disebut dengan variabel laten produk.

Personal (Konsumen) menurut Kotler dan Keller (2009) dalam Verina (2014) keputusan pembeli (konsumen) juga dipengaruhi oleh karakteristik pribadi. Karakteristik tersebut meliputi usia dan tahap dalam siklus hidup, pekerjaan, keadaan ekonomi, gaya hidup, nilai, kepribadian dan konsep diri pembeli.

Budaya merupakan kompleks simbol, nilai, gagasan, serta barang-barang buatan manusia (artifacts) yang diciptakan oleh masyarakat tertentu dan diwariskan turun-temurun sebagai faktor penentu (determinants) dan pengatur (regulator) perilaku anggotanya. Beberapa sikap dan perilaku yang dipengaruhi oleh budaya: (1) rasa diri dan ruang, (2) komunikasi dan bahasa, (3) pakaian dan penampilan, (4) makanan dan kebiasaan makan, (5) waktu dan kesadaran akan waktu, (6) hubungan sosial, (7) nilai dan norma, (8) kepercayaan dan sikap, (9) proses mental dan pembelajaran dan (10) kebiasaan kerja dan praktik. Elemen lain yang membedakan setiap kultur budaya antara lain: nilai, bahasa, mitos, adat, ritual, dan hukum (Setiadi, 2003).

\section{METODE PENELITIAN}

Populasi dari penelitian ini adalah masyarakat yang berada di kabupaten Gianyar, dengan sampel yaitu masyarakat Gianyar yang telah berumur 18 tahun keatas, mengetahui, pernah membeli serta pernah mengonsumsi buah impor.

Penelitian ini menggunakan teknik Sampling aksidental, yaitu teknik penentuan sampel berdasarkan kebetulan. Teknik ini memungkinkan peneliti mengambil sampel penelitian dari siapapun yang secara kebetulan ditemui dan dipandang sesuai sebagai sumber data, sampai jumlah yang diharapkan terpenuhi.

Teknik analisis data. Analisis structural equation modeling (SEM) digunakan pada penelitian ini. Menurut Hair dkk (2013) tahapan dari analisis SEM sebagai berikut:

- mendefinisikan variabel laten

- mengembangkan dan menentukan model pengukuran,

- merancang model penelitian, 
- menilai validitas model pengukuran,

- menentukan model structural, dan

- menilai validitas model struktural.

Variabel laten yang digunakan yaitu: persepsi konsumen tentang konsumsi buah impor (persepsi), pengetahuan konsumen tentang buah impor (produk), pengalaman/ pandangan konsumen dalam pemanfaatan buah impor (personal) dan budaya tentang pemanfaatan buah impor dalam upacara adat (budaya), dengan variabel terukur yaitu:

Tabel 2.1 Variabel Penelitian

\begin{tabular}{|c|c|l|}
\hline Laten & Simbol & \\
\hline \multirow{5}{*}{ Persepsi } & $\mathrm{Y}_{\mathrm{s} 1}$ & Minat beli \\
& $\mathrm{Y}_{\mathrm{s} 2}$ & Membeli produk setiap hari \\
& $\mathrm{Y}_{\mathrm{s} 3}$ & Keputusan membeli karena layak \\
& $\mathrm{Y}_{\mathrm{s} 4}$ & Pendapat tentang produk \\
\hline \multirow{5}{*}{ Produk } & $\mathrm{Y}_{\mathrm{s} 5}$ & Kebutuhan untuk sehari-hari \\
& $\mathrm{X}_{\mathrm{s} 1}$ & Ukuran buah \\
& $\mathrm{X}_{\mathrm{s} 2}$ & Promosi oleh penjual \\
& $\mathrm{X}_{\mathrm{s} 3}$ & Lokasi yang bersih dan nyaman \\
& $\mathrm{X}_{\mathrm{s} 4}$ & Warna buah yang dibeli baik \\
& $\mathrm{X}_{\mathrm{s} 5}$ & Harga terjangkau \\
& $\mathrm{X}_{\mathrm{s} 6}$ & Kebersihan kulit buah \\
& $\mathrm{X}_{\mathrm{s} 7}$ & Rasa buah enak \\
& $\mathrm{X}_{\mathrm{s} 8}$ & Dibeli dalam keadaan segar \\
\hline \multirow{5}{*}{ Personal } & $\mathrm{X}_{\mathrm{s} 9}$ & Pengalaman membeli buah \\
& $\mathrm{X}_{\mathrm{s} 10}$ & Sering melihat, membeli atau mengkonsumsi buah \\
& $\mathrm{X}_{\mathrm{s} 11}$ & Harapan dari buah yang ingin dibeli \\
& $\mathrm{X}_{\mathrm{s} 12}$ & Mempunyai alasan dalam membeli buah \\
& $\mathrm{X}_{\mathrm{s} 13}$ & Mengetahui produk yang dibeli \\
\hline \multirow{5}{*}{} & $\mathrm{X}_{\mathrm{s} 14}$ & Penting keberadaanya dalam upacara adat \\
& $\mathrm{X}_{\mathrm{s} 15}$ & Penggunaan pada upacara adat diterima oleh masyarakat \\
& $\mathrm{X}_{\mathrm{s} 16}$ & Terbiasa menggunakan pada suatu upacara adat \\
& $\mathrm{X}_{\mathrm{s} 17}$ & Tidak ada larangan penggunaan dalam upacara adat \\
& $\mathrm{X}_{\mathrm{s} 18}$ & Dapat digunakan sebagai simbol dalam suatu upacara adat \\
& $\mathrm{X}_{\mathrm{s} 19}$ & Nyaman membahas dengan masyarakat sekitar \\
& $\mathrm{X}_{\mathrm{s} 20}$ & Percaya bahwa buah baik digunakan untuk upacara adat \\
& $\mathrm{X}_{\mathrm{s} 21}$ & Komentar baik dari masyarakat sekitar \\
\hline & & \\
& & \\
& &
\end{tabular}

\section{HASIL DAN PEMBAHASAN}

\section{Mendefinisikan Variabel Laten}

Persepsi, produk dan budaya adalah variabel-variabel laten pada penelitian ini, dengan variabel terhitung pada masing-masing variabel laten sesuai dengan Tabel 2.1.

\section{Mengembangkan dan Menentukan Model Pengukuran}

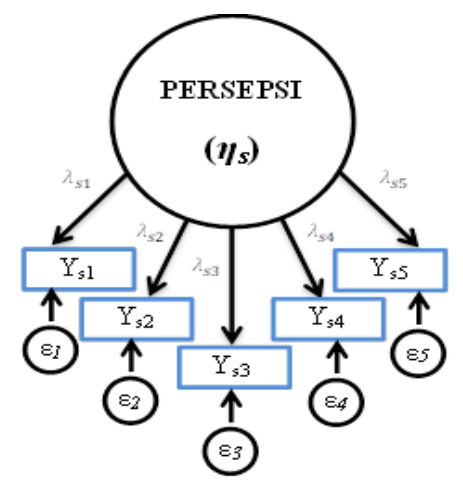

Gambar 3.1 Model Pengukuran Variabel Laten Persepsi 


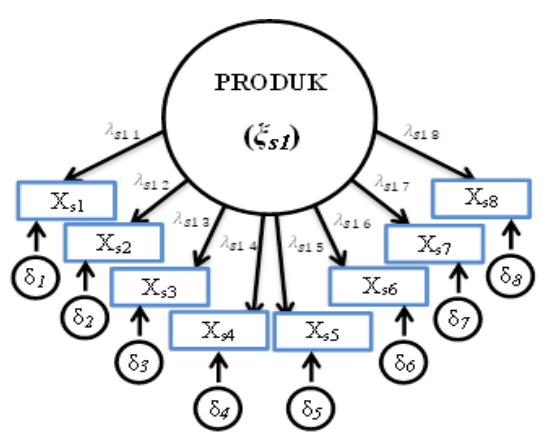

Gambar 3.2 Model Pengukuran Variabel Laten Produk.

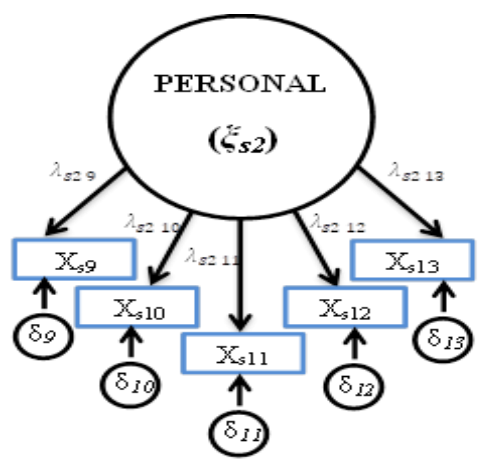

Gambar 3.3 Model Pengukuran Variabel Laten Personal.

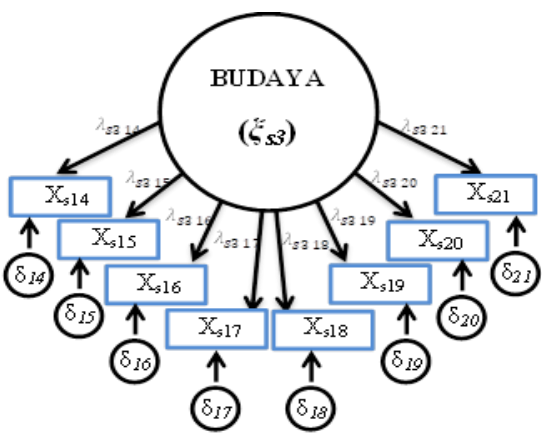

Gambar 3.4 Model Pengukuran Variabel Laten Budaya.

dengan persamaan model pengukuran sebagai berikut:

\section{Persepsi}

$\begin{array}{ll}\mathrm{Y}_{\mathrm{s} 1}=\lambda_{s 1} \eta_{\mathrm{s}}+\varepsilon_{1} & \mathrm{X}_{\mathrm{s} 9}=\lambda_{s 29} \xi_{\mathrm{s} 2}+\delta_{9} \\ \mathrm{Y}_{\mathrm{s} 2}=\lambda_{s 2} \eta_{\mathrm{s}}+\varepsilon_{2} & \mathrm{X}_{\mathrm{s} 10}=\lambda_{s 210} \xi_{\mathrm{s} 2}+\delta_{10} \\ \mathrm{Y}_{\mathrm{s} 3}=\lambda_{s 3} \eta_{\mathrm{s}}+\varepsilon_{3} & \mathrm{X}_{\mathrm{s} 11}=\lambda_{s 211} \xi_{\mathrm{s} 2}+\delta_{11} \\ \mathrm{Y}_{\mathrm{s} 4}=\lambda_{s 4} \eta_{\mathrm{s}}+\varepsilon_{4} & \mathrm{X}_{\mathrm{s} 12}=\lambda_{s 212} \xi_{\mathrm{s} 2}+\delta_{12} \\ \mathrm{Y}_{\mathrm{s} 5}=\lambda_{s 5} \eta_{\mathrm{s}}+\varepsilon_{5} & \mathrm{X}_{\mathrm{s} 13}=\lambda_{s 213} \xi_{\mathrm{s} 2}+\delta_{13}\end{array}$

Produk

$\mathrm{X}_{\mathrm{s} 1}=\lambda_{s 11} \xi_{\mathrm{s} 1}+\delta_{1}$

$\mathrm{X}_{\mathrm{s} 2}=\lambda_{\mathrm{s} 12} \xi_{\mathrm{s} 1}+\delta_{2}$

$\mathrm{X}_{\mathrm{s} 3}=\lambda_{\mathrm{s} 13} \xi_{\mathrm{s} 1}+\delta_{3}$

$\mathrm{X}_{\mathrm{s} 4}=\lambda_{s 14} \xi_{\mathrm{s} 1}+\delta_{4}$

$\mathrm{X}_{\mathrm{s} 5}=\lambda_{\mathrm{s} 15} \xi_{\mathrm{s} 1}+\delta_{5}$

$\mathrm{X}_{\mathrm{s} 6}=\lambda_{\mathrm{s} 16} \xi_{\mathrm{s} 1}+\delta_{6}$

$\mathrm{X}_{\mathrm{s} 7}=\lambda_{s 17} \xi_{\mathrm{s} 1}+\delta_{7}$

$\mathrm{X}_{\mathrm{s} 8}=\lambda_{s 18} \xi_{\mathrm{s} 1}+\delta_{8}$
Budaya

$\mathrm{X}_{\mathrm{s} 14}=\lambda_{s 314} \xi_{\mathrm{s} 3}+\delta_{14}$
$\mathrm{X}_{\mathrm{s} 15}=\lambda_{s 315} \xi_{\mathrm{s} 3}+\delta_{15}$
$\mathrm{X}_{\mathrm{s} 16}=\lambda_{s 316} \xi_{\mathrm{s} 3}+\delta_{16}$
$\mathrm{X}_{\mathrm{s} 17}=\lambda_{s 317} \xi_{\mathrm{s} 3}+\delta_{17}$
$\mathrm{X}_{\mathrm{s} 18}=\lambda_{s 318} \xi_{\mathrm{s} 3}+\delta_{18}$
$\mathrm{X}_{\mathrm{s} 19}=\lambda_{s 319} \xi_{\mathrm{s} 3}+\delta_{19}$
$\mathrm{X}_{\mathrm{s} 20}=\lambda_{s 320} \xi_{\mathrm{s} 3}+\delta_{20}$
$\mathrm{X}_{\mathrm{s} 21}=\lambda_{s 321} \xi_{\mathrm{s} 3}+\delta_{21}$

$\mathrm{X}_{\mathrm{s} 14}=\lambda_{s 314} \xi_{\mathrm{s} 3}+\delta_{14}$ ${ }_{53}+\delta_{16}$ $\mathrm{X}_{\mathrm{s} 17}=\lambda_{s 317} \xi_{\mathrm{s} 3}+\delta_{17}$ $\mathrm{X}_{\mathrm{s} 18}=\lambda_{s 318} \xi_{\mathrm{s} 3}+\delta_{18}$ $\mathrm{X}_{\mathrm{s} 20}=\lambda_{\mathrm{s} 320} \xi_{\mathrm{s} 3}+\delta_{20}$ $\mathrm{X}_{\mathrm{s} 21}=\lambda_{s 321} \xi_{\mathrm{s} 3}+\delta_{21}$

\section{Merancang Model Penelitian}

Pada penelitian ini, matriks yang digunakan dalam menganalisis data adalah matriks kovarians dengan teknik estimasi maximum likelihood estimation (MLE). Menggunakan 164 sampel, dimana peneliti mengambil sampel menggunakan kuesioner tertutup.

\section{Menilai Validitas Model Pengukuran}

Tabel 3.1 Validitas dan Reabilitas Data

\begin{tabular}{|c|c|c|c|}
\hline Laten & Variabel & $\begin{array}{l}\text { Corrected } \\
\text { Item-Total } \\
\text { Correlation }\end{array}$ & $\begin{array}{l}\text { Cronbach's } \\
\text { Alpha }\end{array}$ \\
\hline \multirow{5}{*}{ 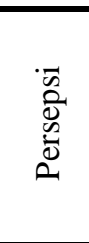 } & $\mathrm{Y}_{\mathrm{s} 1}$ & 0,497 & \multirow{5}{*}{0,729} \\
\hline & $\mathrm{Y}_{\mathrm{s} 2}$ & 0,545 & \\
\hline & $Y_{\mathrm{s} 3}$ & 0,408 & \\
\hline & $Y_{s 4}$ & 0,518 & \\
\hline & $Y_{\mathrm{s} 5}$ & 0,483 & \\
\hline \multirow{8}{*}{$\begin{array}{l}\frac{y}{3} \\
\frac{0}{0} \\
=\end{array}$} & $\mathrm{X}_{\mathrm{s} 1}$ & 0,487 & \multirow{8}{*}{0,793} \\
\hline & $X_{\mathrm{s} 2}$ & 0,498 & \\
\hline & $X_{\mathrm{s} 3}$ & 0,550 & \\
\hline & $X_{s 4}$ & 0,551 & \\
\hline & $X_{\mathrm{s} 5}$ & 0,358 & \\
\hline & $X_{\mathrm{s} 6}$ & 0,565 & \\
\hline & $X_{s 7}$ & 0,623 & \\
\hline & $\mathrm{X}_{\mathrm{s} 8}$ & 0,520 & \\
\hline \multirow{5}{*}{ 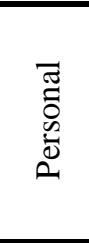 } & $\mathrm{X}_{\mathrm{s} 9}$ & 0,182 & \multirow{5}{*}{0,555} \\
\hline & $X_{\mathrm{s} 10}$ & 0,193 & \\
\hline & $\mathrm{X}_{\mathrm{s} 11}$ & 0,464 & \\
\hline & $X_{s 12}$ & 0,379 & \\
\hline & $X_{s 13}$ & 0,400 & \\
\hline \multirow{8}{*}{ 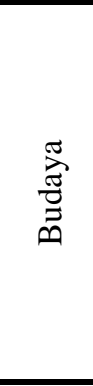 } & $\mathrm{X}_{\mathrm{s} 14}$ & 0,460 & \multirow{8}{*}{0,858} \\
\hline & $X_{\mathrm{s} 15}$ & 0,611 & \\
\hline & $X_{\mathrm{s} 16}$ & 0,668 & \\
\hline & $X_{s 17}$ & 0,606 & \\
\hline & $\mathrm{X}_{\mathrm{s} 18}$ & 0,601 & \\
\hline & $\mathrm{X}_{\mathrm{s} 19}$ & 0,578 & \\
\hline & $X_{\mathrm{s} 20}$ & 0,637 & \\
\hline & $\mathrm{X}_{\mathrm{s} 21}$ & 0,629 & \\
\hline
\end{tabular}


Variabel terukur dikatakan valid apabila memiliki nilai korelasi dengan semua variabel terukur pada variabel laten yang sama lebih besar atau sama dengan 0,3 (Churchill, 1979) dan Instrumen dikatakan reliabel apabila memiliki nilai cronbach alpha lebih besar atau sama dengan 0,60 (Hair et al, 2013). Sehingga variabel terukur $X_{\mathrm{s} 9}$ dan $X_{\mathrm{s} 10}$ pada variabel laten personal bukan variabel terukur yang valid.

Variabel yang tidak valid tersebut di eleminasi sampai diproleh variabel yang valid dengan variabel laten yang reliabel, dan diperoleh hasil seperti pada Tabel 3.2.

Tabel 3.2 Validitas dan Reabilitas Data dengan Eleminasi X9 dan X10

\begin{tabular}{|c|c|c|c|}
\hline Laten & Variabel & $\begin{array}{c}\text { Corrected } \\
\text { Item-Total } \\
\text { Correlation } \\
\end{array}$ & $\begin{array}{c}\text { Cronbach's } \\
\text { Alpha }\end{array}$ \\
\hline \multirow{5}{*}{$\begin{array}{l}\bar{n} \\
\bar{D} \\
\bar{\omega} \\
0\end{array}$} & $\overline{Y_{\mathrm{s} 1}}$ & 0,497 & \multirow{5}{*}{0,729} \\
\hline & $\mathrm{Y}_{\mathrm{s} 2}$ & 0,545 & \\
\hline & $\mathrm{Y}_{\mathrm{s} 3}$ & 0,408 & \\
\hline & $Y_{\mathrm{s} 4}$ & 0,518 & \\
\hline & $Y_{s 5}$ & 0,483 & \\
\hline \multirow{8}{*}{$\begin{array}{l}\frac{y}{3} \\
0 \\
0 \\
0\end{array}$} & $\mathrm{X}_{\mathrm{s} 1}$ & 0,487 & \multirow{8}{*}{0,793} \\
\hline & $X_{\mathrm{s} 2}$ & 0,498 & \\
\hline & $X_{\mathrm{s} 3}$ & 0,550 & \\
\hline & $X_{s 4}$ & 0,551 & \\
\hline & $X_{\mathrm{s} 5}$ & 0,358 & \\
\hline & $X_{s 6}$ & 0,565 & \\
\hline & $X_{\mathrm{s} 7}$ & 0,623 & \\
\hline & $X_{\mathrm{s} 8}$ & 0,520 & \\
\hline \multirow{3}{*}{ 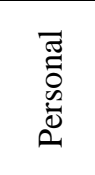 } & $X_{\mathrm{s} 11}$ & 0,464 & \multirow{3}{*}{0,605} \\
\hline & $\mathrm{X}_{\mathrm{s} 12}$ & 0,379 & \\
\hline & $\mathrm{X}_{\mathrm{s} 13}$ & 0,400 & \\
\hline \multirow{8}{*}{ 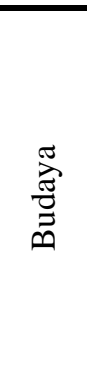 } & $X_{s 14}$ & 0,460 & \multirow{8}{*}{0,858} \\
\hline & $X_{s 15}$ & 0,611 & \\
\hline & $X_{\mathrm{s} 16}$ & 0,668 & \\
\hline & $X_{\mathrm{s} 17}$ & 0,606 & \\
\hline & $X_{\mathrm{s} 18}$ & 0,601 & \\
\hline & $X_{s 19}$ & 0,578 & \\
\hline & $\mathrm{X}_{\mathrm{s} 20}$ & 0,637 & \\
\hline & $X_{s 21}$ & 0,629 & \\
\hline
\end{tabular}

Diperoleh model pengukuran variabel laten personal baru dengan variabel terukur yang valid dan variabel laten reliabel sebagai berikut:

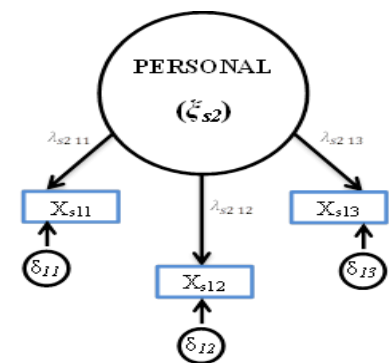

Gambar 3.5 Model pengukuran variabel laten personal dengan validasi.

\section{Personal}

$\mathrm{X}_{\mathrm{s} 11}=$

$$
\lambda_{s 211} \xi_{\mathrm{s} 2}+\delta_{11}
$$

$\mathrm{X}_{\mathrm{s} 12}=$

$$
\lambda_{s 212} \xi_{\mathrm{s} 2}+\delta_{12}
$$

$$
\begin{aligned}
& \mathrm{X}_{\mathrm{s} 13}= \\
& \quad \lambda_{\mathrm{s} 213} \xi_{\mathrm{s} 2}+\delta_{13}
\end{aligned}
$$




\section{Menentukan Model Structural}

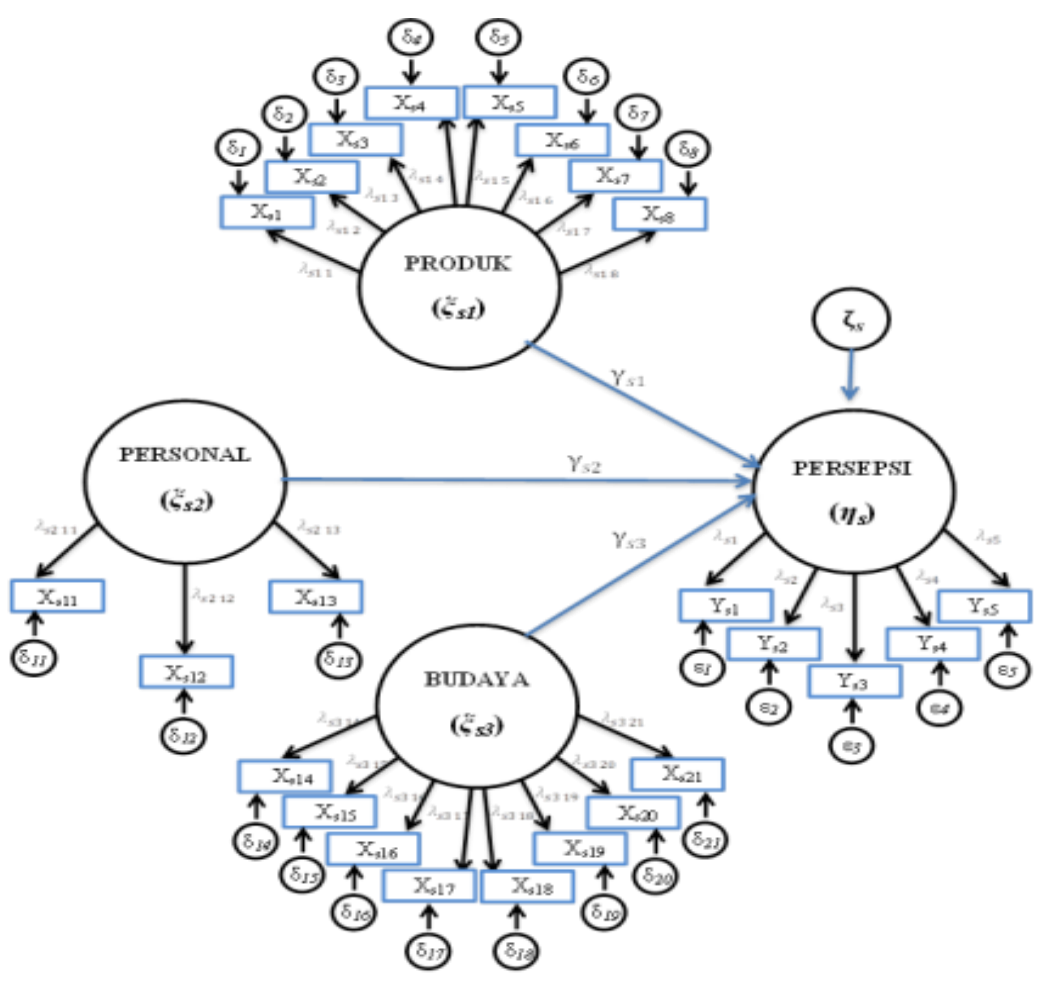

Gambar 3.6 Diagram Model Struktural

\section{Menilai Validitas Model Struktural}

Tabel 3.3 Validitas Model Struktural

\begin{tabular}{|llll|}
\hline $\begin{array}{c}\text { Goodness } \\
\text { of fit index }\end{array}$ & $\begin{array}{c}\text { Cut-off } \\
\text { Value }\end{array}$ & Hasil & Keterangan \\
\hline Chi-Square & $<\mathrm{df}$ & 525,46 & Tidak fit \\
RMSEA & $\leq 0,08$ & 0,083 & Tidak fit \\
GFI & $\geq 0,90$ & 0,785 & Tidak fit \\
TLI & $\geq 0,90$ & 0,749 & Tidak fit \\
Cmin/DF & $\leq 2,00$ & 2,110 & Tidak fit \\
\hline
\end{tabular}

dengan nilai $\mathrm{df}$ buah impor $=249$.

Karena hasil goodness of fit yang diperoleh menunjukan model yang tidak fit, peneliti melakukan modifikasi pada model struktural tersebut dengan menambahkan hubungan antara dua variabel laten eksogen (produk, personal, dan budaya) sampai diperoleh model terbaik. Diperoleh nilai goodness-of-fit terbaik pada Tabel 3.4 dengan diagram model baru pada Gambar 3.6.
Tabel 3.4 Validitas Model Struktural Baru

\begin{tabular}{|lccc|}
\hline $\begin{array}{c}\text { Goodness } \\
\text { offit } \\
\text { index }\end{array}$ & $\begin{array}{c}\text { Cut-off } \\
\text { Value }\end{array}$ & Hasil & Keterangan \\
\hline $\begin{array}{l}\text { Chi- } \\
\text { Square }\end{array}$ & $<\mathrm{df}$ & 454,19 & Tidak fit \\
RMSEA & $\leq 0,08$ & 0,072 & Good fit \\
GFI & $\geq 0,90$ & 0,808 & Marginal fit \\
TLI & $\geq 0,90$ & 0,809 & Marginal fit \\
Cmin/DF & $\leq 2,00$ & 1,846 & Good fit \\
\hline
\end{tabular}

pada Tabel 3.4 hasil goodness-of-fit telah menunjukkan model yang cocok, dengan empat kriteria RMSEA, Cmin/Df yang baik, dan GFI, TLI yang dapat diterima. Hal ini menunjukkan variabel terukur mampu menjelaskan dengan baik variabel latennya (Abdullah, dkk., 2019). Pada pembahasan selanjutnya, model yang digunakan adalah model dengan modifikasi (model terbaik). 


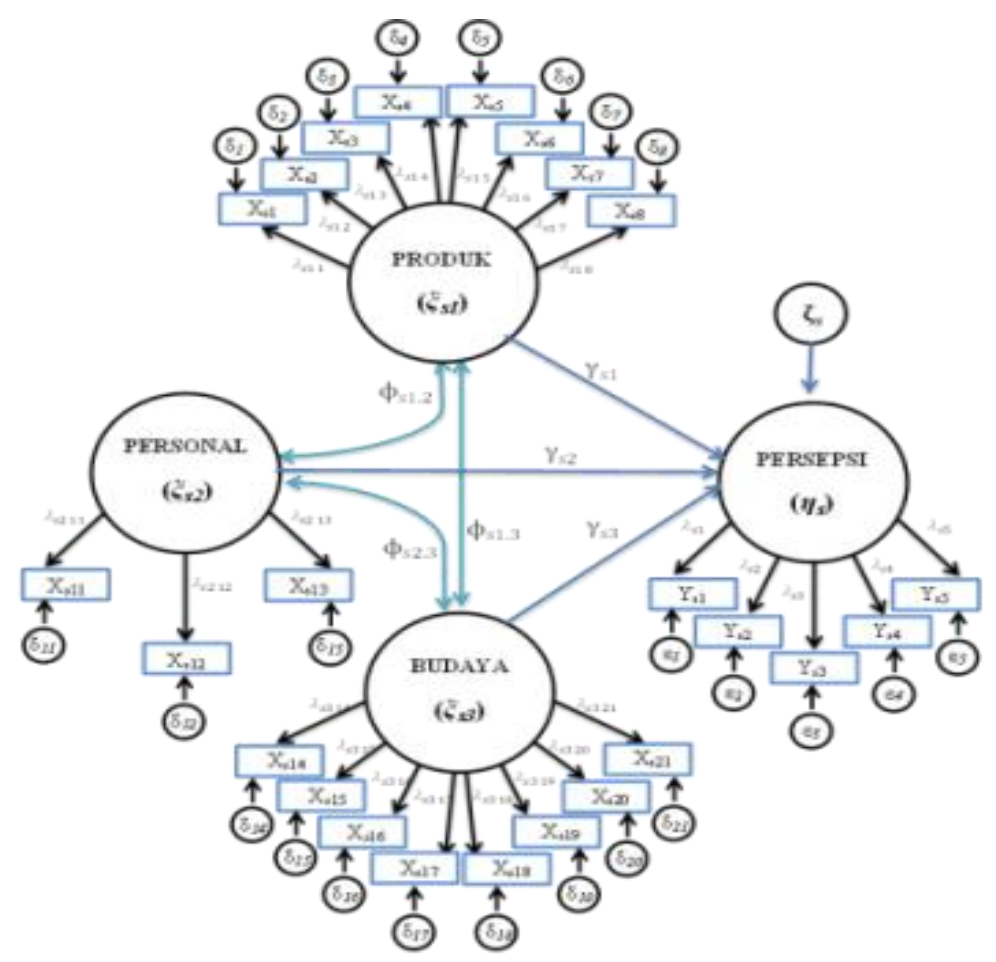

Gambar 3.7 Diagram Model Struktural yang Telah Dimodifikasi

Tabel 3.5 Nilai Koefisen Jalur dan p-value.

\begin{tabular}{|lccc|}
\hline $\begin{array}{c}\text { Variabel } \\
\text { laten }\end{array}$ & $\begin{array}{c}\text { Nilai } p \text { - } \\
\text { value }\end{array}$ & $\begin{array}{c}\text { Signifik } \\
\text { ansi }\end{array}$ & $\begin{array}{c}\text { Koefisien } \\
\text { jalur }\end{array}$ \\
\hline $\begin{array}{l}\text { Produk } \\
\left(\xi_{s 1}\right)\end{array}$ & 0,004 & Sig. & 0,440 \\
$\begin{array}{l}\text { Personal } \\
\left(\xi_{s 2}\right)\end{array}$ & 0,690 & $\begin{array}{c}\text { Tidak } \\
\text { sig. }\end{array}$ & $-0,133$ \\
$\begin{array}{l}\text { Budaya } \\
\left(\xi_{s 3}\right)\end{array}$ & 0,058 & Sig. & 0,280 \\
\hline
\end{tabular}

Berdasarkan Tabel 3.5 diperoleh model sebagai berikut:

$$
\begin{aligned}
\eta_{s}= & 0,440\left[\xi_{s 1}\right]-0,133\left[\xi_{s 2}\right] \\
& +0,280\left[\xi_{s 3}\right]+\zeta_{s}
\end{aligned}
$$

Pada Tabel 3.5 diperoleh pula nilai koefisien jalur variabel laten produk dan budaya pada buah impor bernilai positif, berarti semakin tinggi tingkat pengetahuan konsumen tentang produk (produk) dan budaya tentang pemanfaatan buah-buahan dalam upacara adat (budaya), maka tingkat persepsi konsumen tentang konsumi buah impor (persepsi) akan meningkat. Sedangkan laten personal bernilai negative, berarti semakin tinggi pengalaman/pandangan konsumen dalam pemanfaatan buah (personal) maka tingkat persepsi konsumen tentang konsumi buah impor (persepsi) akan menurun. Variabel produk adalah variabel yang berpengaruh terbesar terhadap persepsi konsumen dalam membeli buah impor, sedangkan variabel laten personal paling kecil memengaruhi persepsi konsumen dalam membeli buah impor.

\section{KESIMPULAN DAN SARAN}

\section{Kesimpulan}

Variabel laten produk berpengaruh signifikan pada taraf 5\% terhadap persepsi konsumen dalam membeli buah impor, variabel laten budaya berpengaruh signifikan pada taraf $10 \%$ terhadap persepsi konsumen dalam membeli buah impor, sedangkan variabel laten personal tidak berpengaruh signifikan.

Variabel laten produk adalah variabel laten dominan yang memengaruhi persepsi konsumen dalam membeli buah impor.

\section{Saran}

Pada penelitian selanjutnya, diharapkan dapat menambahkan variabel laten maupun variabel terukur pada setiap variabel laten dengan dukungan teori yang kuat dan memperluas daerah pengambilan sampel penelitian. 


\section{DAFTAR PUSTAKA}

Abdullah, S., Kholil, \& Purnomo, A. 2019. Application of Structural Equation Modeling (SEM) for Analysis of the Effect of Perception on Professionality, Knowledge and Motivation of Nurses on the Implementation of Patients Safety Programs. Asian Journal of Research in Nursing and Health, 1-12.

Byrne, B. M. 2010. Structural Equation Modeling with AMOS: Basic Concepts, Applications, and Programming (2nd ed.). New York: Taylor and Francis Group, LLC.

Carvalho, J. d., \& Chima, F. O. 2014. Applications of Structural Equation Modeling in Social Sciences Research. American International Journal of Contemporary Research, 4.

Churchill JR, G. A. 1979. A Paradigm for Developing Better Measures of Marketing Constructs. JMR. Journal of Marketing Research (pre-1986), 64-73.

Dwiastuti, R., Shinta, A., \& Isaskar, R. 2012. Ilmu Perilaku Konsumen (1st ed.). (T. U. Press, Ed.) Malang: UB Press.

Ghozali, I. 2005. Model Persamaan Struktural: Konsep dan Aplikasi dengan Program AMOS ver.5.0 (2nd ed.). Semarang: Universitas Diponogoro.

Hair JR, J. F., Black, W. C., Babin, B. J., \& Anderson, R. E. 2013. Multivariate Data
Analysis (7th ed.). Pearson Education Limited.

Kenyon, G. N., \& Sen, K. C. 2015. The Perception of Quality: Mapping Product and Service Quality to Consumer Perception. London: Springer.

Mattjik, A. A., \& Sumertajaya, I. 2011. Sidik| Peubah Ganda: Dengan Menggunakan SAS (1st ed.). Bogor: IPB PRESS.

Nurchayati, \& Hikmah. 2014. Distribusi Buah Lokal dan buah Imort (Studi Kasus pada Pedagang Buah di Kota Semarang). Serat Acitya-jurnal Ilmiah UNTAG Semarang, 17-29.

Nurchayati, \& Hikmah. 2014. Distribusi Buah Lokal dan buah Import (Studi Kasus pada Pedagang Buah di Kota Semarang). Serat Acitya-jurnal Ilmiah UNTAG Semarang, 7, 17-29.

Sarwono, J. 2010. Pengertian Dasar Structural Equation Modeling (SEM). Jurnal Ilmiah Manajemen Bisnis, 10, 173-182.

Schumacker, R. E., \& Lomax, R. G. 2016. A Beginner's Guide to Structural Equation Modeling (4nd ed.). New York: Routledge.

Setiadi, N. J. 2003. Perilaku Konsumen: Konsep dan Implikasi untuk Strategi dan Penelitian Pemasaran (1st ed.). Bogor: Kencana.

Timm, N. H. 2002. Applied Multivariate Analysis. New York: Springer. 